\title{
1. EXPLANATORY NOTES: DEEP SEA DRILLING PROJECT LEG 96, MISSISSIPPI FAN, GULF OF MEXICO ${ }^{1}$
}

\author{
Audrey W. Meyer, Deep Sea Drilling Project, Scripps Institution of Oceanography ${ }^{2}$
}

These explanatory notes are intended to help the reader understand the Leg 96 site chapters that follow. Although the Leg 96 shipboard party by and large followed standard Deep Sea Drilling Project (DSDP) procedures, every DSDP cruise has procedural peculiarities that result from the personalities and interests of the shipboard scientists and from the overall scientific objectives. This chapter outlines standard DSDP shipboard procedures and details Leg 96 deviations from them.

\section{RESPONSIBILITY OF AUTHORSHIP}

Site summary chapters are coauthored by the entire shipboard scientific party; ultimate responsibility for their content lies with the two Co-Chief Scientists and the DSDP Shipboard Science Representative. The Leg 96 site chapters are organized into the following sections:

Site Summary

Background and Objectives

Operations

Seismic Stratigraphy and Acoustic Facies

Biostratigraphy and Sedimentation Rates

Lithostratigraphy

Geochemistry

Physical Properties

Summary and Conclusions

Data and preliminary interpretations in the site chapters reflect knowledge gleaned only from shipboard and very initial postcruise analyses. Results of the more detailed shore-based work presented in the second portion of this volume may necessitate some reinterpretation of these preliminary site chapters.

The site chapters in this volume are grouped geographically, rather than chronologically. Site chapters for each group of sites follow an introductory chapter detailing the general morphologic setting and summarizing the drilling results at the sites. The drill sites are grouped as follows: (1) middle fan sites (Sites 621, 622, 617, and 620), (2) lower fan sites (Sites 623, 624, 615, and 614), (3) fan margin site (Site 616), and (4) intraslope basin sites (Sites 619 and 618). Because middle fan Site 621 is first in this organizational scheme, much of the information about shipboard activities that generally applies to all the Leg 96 sites is in this site chapter and is not repeated in later site chapters.

\footnotetext{
${ }^{1}$ Bouma, A. H., Coleman, J. M., Meyer, A. W., et al., Init. Repts. DSDP, 96: Washington (U.S. Govt. Printing Office).

Address: (present address) Ocean Drilling Program, Texas A\&M University, College Station, TX 77843-3469.
}

\section{SURVEY AND DRILLING DATA}

The survey data used for specific site selections are discussed in each site chapter. En route between sites, continuous observations were made of depth, magnetic field, and sub-bottom structure. Short surveys using a precision echo sounder, seismic profiles, and a magnetometer were made on Glomar Challenger before dropping the beacon.

The seismic-profiling system consisted of either an 80 -in. ${ }^{3}$ water gun or two Bolt air guns, a Scripps-designed hydrophone array, Bolt amplifiers, two bandpass filters, and two EDO recorders, usually recording at two different filter settings.

The depths of reflectors on seismic profiles were calculated using the following quadratic equation:

$$
D=0.762 R+0.00016 R^{2}
$$

where $R=$ two-way traveltime in milliseconds, and $D=$ sub-bottom depth in meters. This equation was derived from a least-squares fit to interval velocity data collected at an industry drill site located immediately north of the Mississippi Canyon on the slope.

While we were underway, depths were continuously recorded on a Gifft precision graphic recorder. The depths were read on the basis of an assumed $1463 \mathrm{~m} / \mathrm{s}$ sound velocity. The water depth (in meters) at each site was corrected (1) according to the tables of Matthews (1939) and (2) for the depth of the hull transducer $(6 \mathrm{~m})$ below sea level. In addition, depths referred to the drilling platform level are assumed to be $10 \mathrm{~m}$ above the water line.

\section{DRILLING CHARACTERISTICS}

Because water circulation down the hole is open, cuttings are lost onto the seafloor and cannot be examined. The only available information about sedimentary stratification in uncored or unrecovered intervals, other than that from seismic data or wireline logging results, is from an examination of the behavior of the drill string as observed on the drill platform. The harder the layer being drilled, the slower and more difficult it usually is to penetrate. There are, however, a number of other factors that determine the rate of penetration, so it is not always possible to relate it directly to the hardness of the layers. The parameters of bit weight and revolutions per minute are recorded on the drilling recorder and influence the rate of penetration. 


\section{DRILLING DEFORMATION}

When cores are split, many of them show signs of significant sediment disturbance. Such disturbance includes the concave-downward appearance of originally horizontal bands, the haphazard mixing of lumps of different lithologies, and the near-fluid state of some sediments recovered from tens to hundreds of meters below the seafloor. Core deformation probably occurs during one of three different steps at which the core can suffer stresses sufficient to alter its physical characteristics: cutting, retrieval (with accompanying changes in pressure and temperature), and core handling.

\section{SHIPBOARD SCIENTIFIC PROCEDURES}

\section{Numbering of Sites, Holes, Cores, and Samples}

DSDP drill sites are numbered consecutively from the first site drilled by Glomar Challenger in 1968. Site numbers are slightly different from hole numbers. A site number refers to one or more holes drilled while the ship is positioned over a single acoustic beacon. These holes can be within a radius as large as $900 \mathrm{~m}$ from the beacon. Several holes may be drilled at a single site by pulling the drill pipe above the seafloor (out of one hole), moving the ship $20 \mathrm{~m}$ or more from the previous hole, and then drilling another hole.

The first (or only) hole drilled at a site takes the site number. A letter suffix distinguishes each additional hole at the same site. For example: the first hole takes only the site number, the second takes the site number with suffix $\mathrm{A}$, the third takes the site number with suffix B, and so forth. It is important, for sampling purposes, to distinguish the holes drilled at a site because recovered sediments or rocks from cores with the same site number but from different holes usually do not come from equivalent positions in the stratigraphic column.

The cored interval is measured in meters below the seafloor. The depth interval of an individual core is the depth below seafloor that the coring operation began to the depth that the coring operation ended. Each coring interval is generally $9.5 \mathrm{~m}$ long, which is the nominal length of a core barrel. The coring interval may, however, be shorter. "Cored intervals" are not necessarily adjacent to each other, but may be separated by "drilled intervals." In soft sediment, the drill string can be "washed ahead" with the core barrel in place, but not recovering sediment, by pumping water down the pipe at high pressure to wash the sediment out of the way of the bit. If thin, hard rock layers are present, however, it is possible to get "spotty" sampling of these resistant layers within the washed interval, producing a cored interval representing more than $9.5 \mathrm{~m}$.

Cores taken from a hole are numbered serially from the top of the hole downward. Full recovery for a single core is normally $9.3 \mathrm{~m}$ of sediment or rock, which is in a plastic liner $(6.6 \mathrm{~cm}$ i.d.), plus about a 0.2 -m-long sample (without a plastic liner) in a core catcher. The core catcher is a device at the bottom of the core barrel that prevents the core from sliding out while the barrel is be- ing retrieved from the hole. The sediment core, which is in the plastic liner, is then cut into 1.5 -m-long sections that are numbered serially from the top of the sediment core (Fig. 1). When full recovery is obtained, the sections are numbered from 1 through 7 , the last section being shorter than $1.5 \mathrm{~m}$. The core catcher sample is placed below the last section when the core is described, labeled "Core Catcher" (CC), and is treated as a separate section.

When recovery is less than $100 \%$, and if the sediment is contiguous, the recovered sediment is conventionally placed at the top of the cored interval, and then $1.5-\mathrm{m}-$ long sections are numbered serially, starting with Section 1 at the top. There will be as many sections as needed to accommodate the length of the core recovered (Fig. 1); for example, $3 \mathrm{~m}$ of core sample in a plastic liner will be divided into two 1.5 -m-long sections. Sections are cut starting at the top of the recovered sediment, and the last section can be shorter than the normal $1.5 \mathrm{~m}$ length.

When recovery is less than $100 \%$, the original stratigraphic position of the sediment in the cored interval is unknown; we conventionally assign the top of the recovered sediment to the top of the cored interval. This is done for convenience in data handling and for consistency. If recovery is less than $100 \%$ and core fragments are separated, the sections are still numbered serially and the void spaces are preserved while cutting the $1.5-\mathrm{m}$ sections (Fig. 1).

Samples from core sections are designated by distances in centimeters from the top of each section to the top and bottom of the sample interval in that section. A full identification number for a sample consists of the following information: (1) leg, (2) site, (3) hole, (4) core, (5) section, and (6) interval in centimeters. For example, the sample identification number "96-615A-6-3, 98-100 cm" means that a sample was taken between 98 and $100 \mathrm{~cm}$ from the top of Section 3 of Core 6, from the second hole drilled at Site 615 during Leg 96. A sample from the core catcher of this core might be designated "96615A-6,CC (8-9 cm)."

The depth below the seafloor from which a sample numbered "96-615A-6-3, 98-100 cm" was collected is the sum of the depth to the top of the cored interval for Core $6(47.5 \mathrm{~m})$ plus the $3 \mathrm{~m}$ included in Sections 1 and 2 (each $1.5 \mathrm{~m}$ long) plus the $98 \mathrm{~cm}$ below the top of Section 3. The sample in question is therefore from $51.48 \mathrm{~m}$ sub-bottom, which in principle is the sample sub-seafloor depth (sample requests should refer to a specific interval within a core section, rather than the depth below seafloor).

Two types of coring systems were used on the Glomar Challenger during Leg 96: (1) the standard DSDP rotary-coring system and (2) the Advanced Hydraulic Piston Coring/Extended Core Barrel (APC/XCB) system. Conventions regarding the cataloging of $\mathrm{APC} / \mathrm{XCB}$ cores are the same as those for the rotary cores. A full APC/ $\mathrm{XCB}$ core, therefore, consists of six sections, each $1.5 \mathrm{~m}$ long, a seventh section of variable length, and a core catcher as much as $0.2-\mathrm{m}$ long. For details regarding the $\mathrm{APC} / \mathrm{XCB}$ operation, core orientation, and special APC/ $\mathrm{XCB}$ features, see Development and Engineering Tech- 

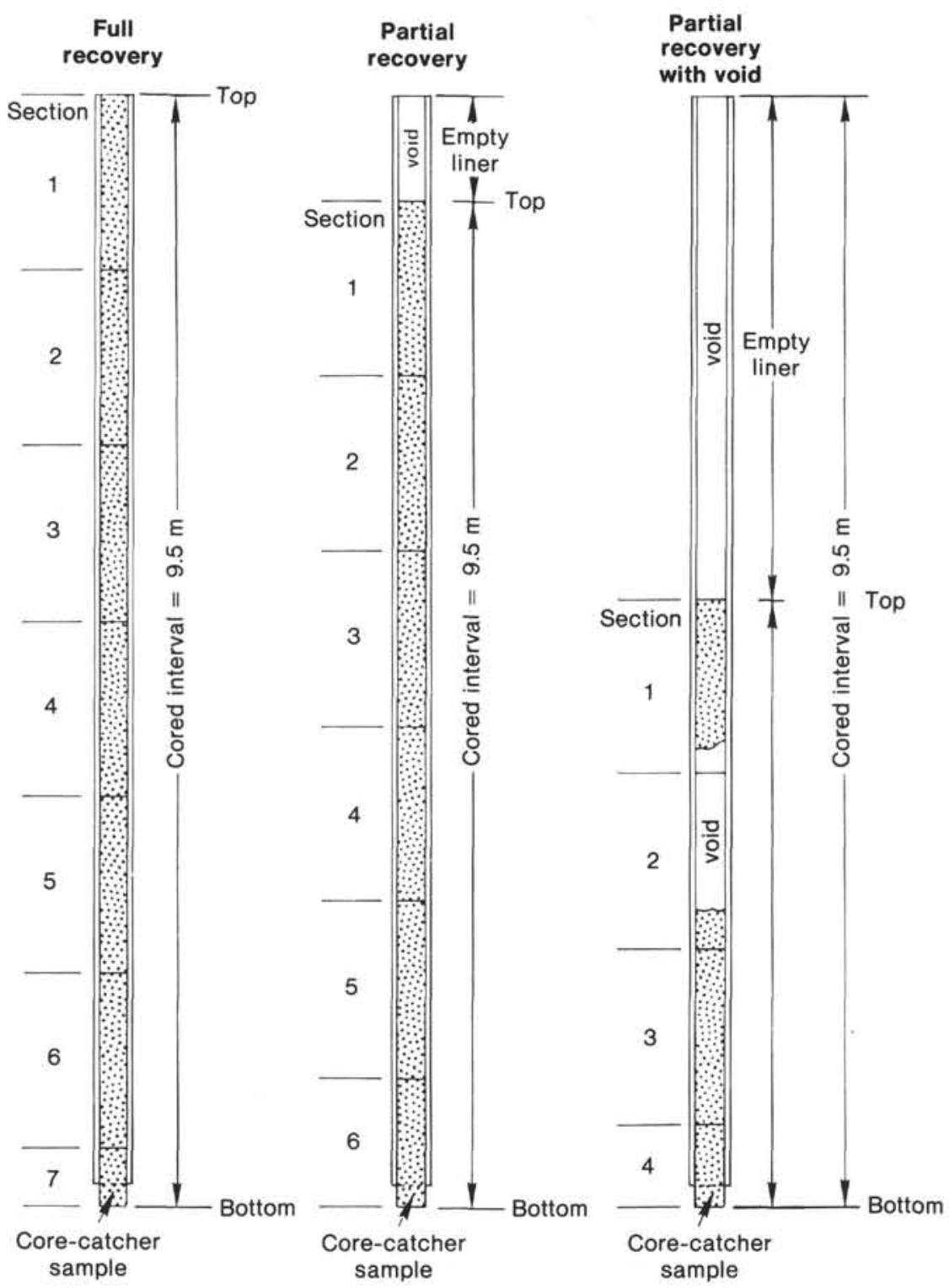

Figure 1. Diagram showing procedure for cutting and labeling of core sections. By convention, sediment from cores with only partial recovery is assumed to have come from the top of the cored interval.

nical Reports Nos. 12, 20, and 21 (available from the Deep Sea Drilling Project).

\section{Handling of Cores}

Cores collected during Leg 96 were normally cut into $1.5-\mathrm{m}$ sections, capped, and labeled; the sections were then brought into the shipboard core laboratory for processing. Continuous wet-bulk density determinations using the Gamma Ray Attenuation Porosity Evaluator (GRAPE) were made on most of the sections before they were split lengthwise.

The cores were then split longitudinally into "work" and "archive" halves with the wire cutter. The first measurements made on the work halves were compressionalwave velocity and vane-shear measurements. Samples subsequently extracted from the work halves included those for (1) shipboard measurement of wet-bulk density by
GRAPE and gravimetric techniques (Boyce, 1976), (2) shipboard measurement of calcium-carbonate percentage with the carbonate bomb (Müller and Gastner, 1971), and (3) numerous shore-based geochemical, paleontological, paleomagnetic, geotechnical, sedimentologic, and petrologic studies.

The color, texture, structure, physical disturbance by the drill bit, and composition of each archive half were described in detail on standard visual core description sheets (one per section). One or more smear slides were made from the sediments recovered in each core and examined by petrographic microscope. The archive half of the core section was then photographed.

After the cores were sampled and described, both the "work" and "archive" halves were maintained in cold storage aboard Glomar Challenger until they were transferred to the DSDP repository at the end of the cruise. 
Samples and whole core sections collected for organic geochemistry studies were frozen immediately on board ship and kept frozen. All Leg 96 cores are presently stored at the Ocean Drilling Program (ODP) East Coast Repository (Lamont-Doherty Geological Observatory).

Visual core description sheets, smear-slide descriptions, paleontologic data, and carbonate bomb (percentage $\mathrm{CaCO}_{3}$ ) determinations (all done aboard ship), provide the data for the summary core descriptions or "barrel sheets" presented at the end of each site chapter in this volume (Fig. 2). Locations of smear-slide and carbonate-bomb samples are shown with a symbol in the "Sample" column of these barrel sheets.

Cores collected on Leg 96 from Holes 615A, 616B, $617 \mathrm{~A}$, and $624 \mathrm{~A}$ were dedicated for shore-based geotechnical studies and were therefore handled differently. They were cut into $1.5-\mathrm{m}$ sections, sealed, labeled, and subjected to GRAPE analysis, but were not split. Instead, they were stored in vertical position in cold storage aboard the Glomar Challenger, shipped to Texas A\&M University at the end of the cruise, and subsequently sampled by shore-based scientists for detailed geotechnical studies (Bryant, Wetzel, Taylor, and Sweet, this volume). Core catchers from Holes $615 \mathrm{~A}, 616 \mathrm{~B}$, and $617 \mathrm{~A}$ were split and described according to standard DSDP procedures. Core catchers from Hole 624A were left unsplit and handled in the same way as the rest of the geotechnical cores.

\section{DESCRIPTION OF SEDIMENTS}

\section{Sediments and Sedimentary Rocks Core Description Form}

\section{Drilling Disturbance}

Recovered materials, particularly soft sediments, may be extremely disturbed. This mechanical disturbance particularly results from the rotary coring technique, which uses a 25 -cm-diameter bit with a 6.2 -cm-diameter opening for the core sample. Hydraulically piston-cored material tends to be less disturbed, but can include significant intervals of flow-in. Symbols for the five disturbance categories used for soft and firm sediment on Leg 96 are shown on the core description form in the column headed "Drilling Disturbance" (Fig. 2). The disturbance categories are defined as follows. (1) Slightly deformed: bedding contacts are slightly bent. (2) Moderately deformed: bedding contacts have undergone extreme bowing. Firm sediment is fractured. (3) Very deformed: bedding is completely disturbed or homogenized by drilling, in some cases showing symmetrical diapirlike structure. (4) Soupy: water-saturated intervals that have lost all aspects of original bedding. (5) Breccia: indurated sediments broken into angular fragments by the drilling process, perhaps along preexisting fractures.

\section{Sedimentary Structures}

It can be extremely difficult to distinguish between natural structures and structures created by the coring process in sediment cores. Where the origin of observed structures is in question, notes to that effect are includ- ed on the core description forms. Locations and types of structures appear as graphic symbols in the column headed "Sedimentary Structures" on the core description form (Fig. 2). Figure 3 gives the key to the symbols used for sedimentary structures recognized in sediments recovered on Leg 96.

\section{Color}

Colors of the core samples were determined with Munsell Soil Color Charts. Colors were determined immediately after the cores were split, while still wet.

\section{Lithology}

Recovered lithologies are represented on the core description forms by a single symbol or by a grouping of two or more symbols (Fig. 4) in the column headed "Graphic Lithologies" (Fig. 2). The symbols in a grouping correspond to end members of sediment constituents, such as clay or nannofossil ooze. The symbol for the terrigenous constituent(s) appears on the right-hand side of the column, the symbol for the biogenic constituent(s) on the left-hand side of the column. The abundance of any component approximately equals the percentage of the width of the graphic column its symbol occupies. For example the left $20 \%$ of the column may have a nannofossil ooze symbol, whereas the right $80 \%$ may have a clay symbol, indicating sediment composed of $80 \%$ clay and $20 \%$ nannofossils.

Much of the material recovered on Leg 96 consisted of normally graded turbidites, so the relative proportions of sand or silt and clay could change dramatically within a single turbidite layer. This change in grain size within each layer is diagrammatically shown in the "Graphic Lithology" column of the core description sheets.

Because of the difference in the length-to-width ratio between the actual sediment core and the graphic lithologic column, it is not possible to reproduce structures as they appear in the core; in the graphic representation they are highly flattened and distorted. The same is true for rock fragments or pebbles in the cores.

\section{Shipboard Analyses}

Smear-slide compositions and carbonate-bomb analyses determined on board Glomar Challenger are listed below the written core description on the core description forms. The locations of these samples in the core are shown in the column entitled "Samples" (Fig. 2). Locations and intervals of whole core samples for organic geochemistry (OGP, WHE, and $\mathrm{KB}$ ), interstitial water (IW), physical property (BRY), and the geotechnical consortium (GTC) are also indicated in this column on the core description forms.

\section{Lithologic Classification of Sediments}

The basic classification system used on Leg 96 was devised by the former Joint Oceanographic Institutions for Deep Earth Sampling (JOIDES) Sedimentary Petrology and Physical Properties Panel (SP4) and adopted for use by the JOIDES Planning Committee in March, 1974. Sediments recovered on Leg 96 include calcareous biogenic sediments, terrigeneous sediments, and volca- 


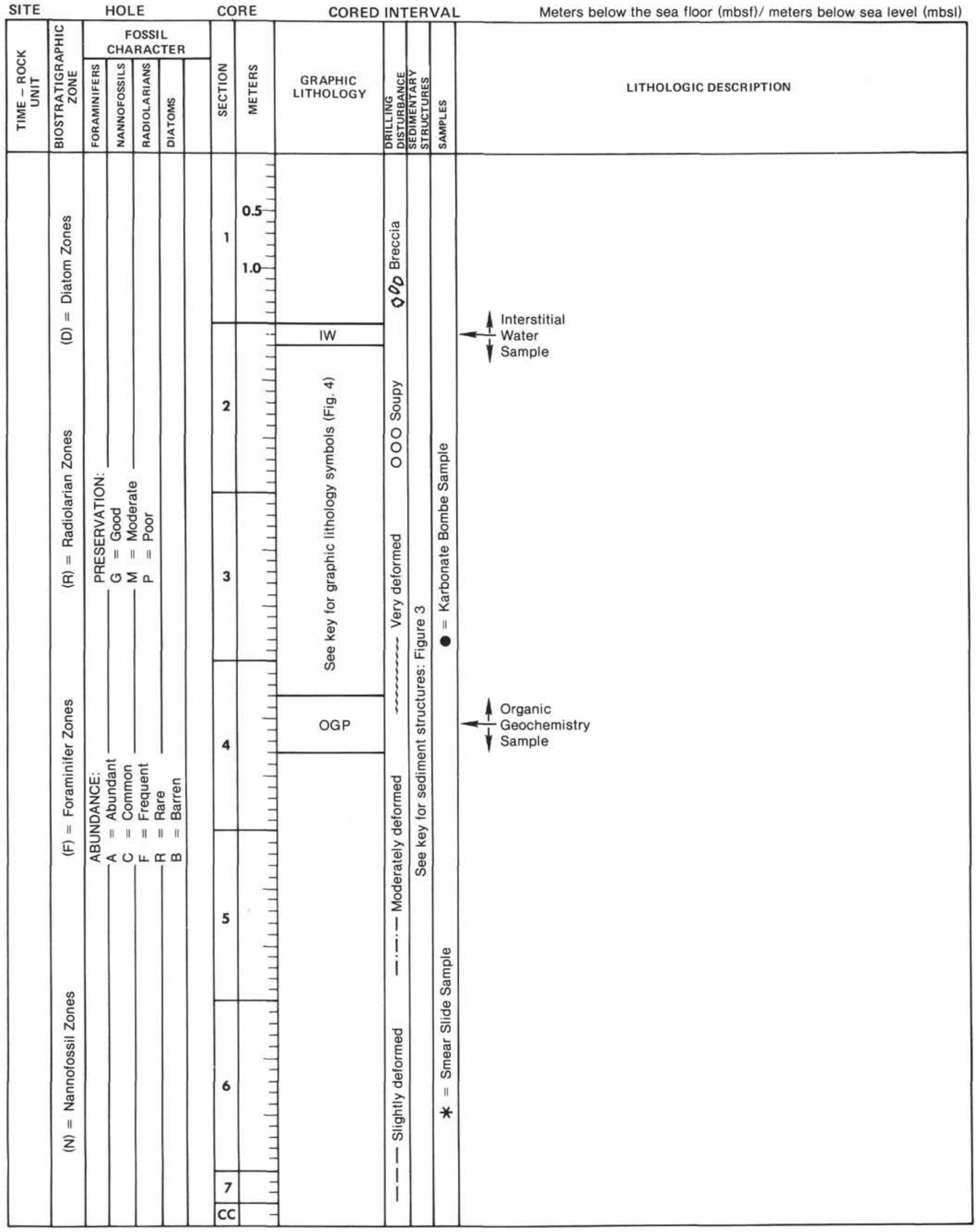

Figure 2. Sample core description form for sediments and sedimentary rocks ("barrel sheets"). 


Current ripples
$\begin{aligned} & \text { Micro-crosslaminae (including } \\ & \text { climbing ripples) }\end{aligned}$
Parallel bedding
W Wavy bedding

Figure 3. Standard symbols for sedimentary structures recognized in sediments recovered during Leg 96 . These symbols are shown in the "Sedimentary Structure" column of the DSDP core description forms (Fig. 2).

nogenic sediments. As pelagic clays and siliceous biogenic sediments were not recovered, they are not described in any detail here; the reader is referred to Supko et al. (1978) for a thorough description of these sediment types.

The DSDP classification used by the Leg 96 sedimentologists is descriptive rather than generic, and categories are based on sediment parameters measured on board ship. Sediment names are those in common usage. A brief outline of the conventions and descriptive data used to construct this classification follows.

\section{Conventions and Descriptive Data}

In this classification scheme, composition and texture are the only criteria used to define the type of sediment or sedimentary rock recovered. Composition is more important for describing sediments deposited in the open ocean, while texture becomes significant for hemipelagic and nearshore sediments such as the majority of those recovered on Leg 96. Compositional and textural data come principally from visual estimates of component percentages in smear slides examined with a petrographic microscope. These data are estimates of areal abundance and size components on the slide and may differ some- what from more accurate analyses of grain size, carbonate content, and mineralogy because of the very small sample used to make a smear slide. Past experience indicates that quantitative estimates of distinctive minor components are accurate to within 1 to $2 \%$, but that accuracy for major constituents is poorer, perhaps only to within $10 \%$. Smear-slide data are verified by carbonatecontent data determined using the carbonate bomb available on board ship.

Where applicable, one or several modifiers are used in naming the type of sediment encountered. In all cases the dominant component appears last in the name; minor components precede, with the least common constituent listed first. Minor constituents occurring in amounts less than $10 \%$ are not normally included in the name.

The degree of induration or lithification of the recovered sediment is reflected in the sediment name. Calcareous sediments and sedimentary rocks are divided into three categories of induration after Gealy et al. (1971); (1) oozes are soft calcareous sediments with little strength that readily deform under the pressure of a finger or the broad blade of a spatula; (2) chalks are firm, partially 
Pelagic biogenic calcareous sediments

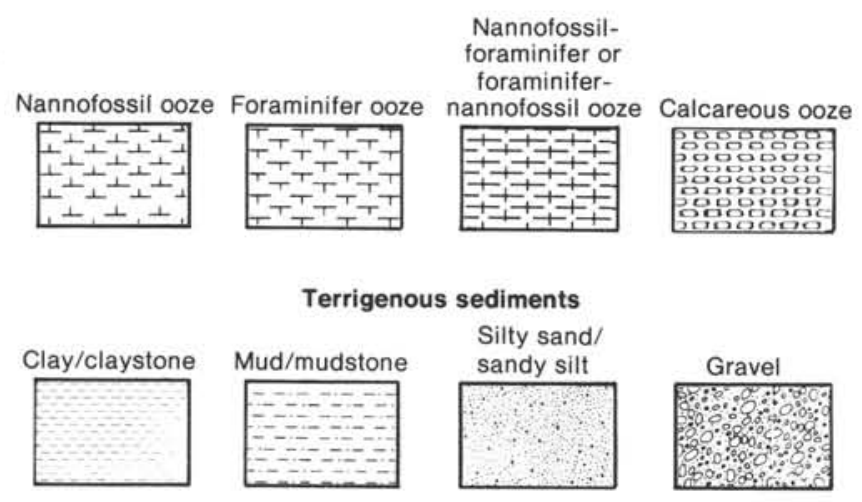

Silty mud/

silty mudstone

Sandy mud/

sandy mudstone Silt/siltstone Sand/sandstone
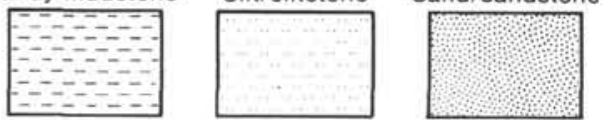

Volcanogenic sediments

Volcanic ash

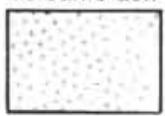

Figure 4. Standard symbols for lithologies drilled during Leg 96. These symbols are shown in the "Graphic Lithology" column of the DSDP core description forms (Fig. 2).

lithified calcareous oozes that are readily scratched with a fingernail or edge of a spatula; (3) limestones are hard, well lithified and cemented calcareous sedimentary rocks that are resistant or impossible to scratch with a fingernail or edge of a spatula. All of the calcareous sediments recovered on Leg 96 were classified as oozes. Terrigenous sediments are called by the sediment name if the material is soft enough for the core to be split with a wire cutter (e.g., silty clay), or by the sediment name plus the suffix stone if the core must be cut with a band saw or diamond saw (e.g., silty claystone).

\section{Types of Sediments, Sedimentary Rocks, and Compositional Boundaries}

\section{Calcareous Biogenic Sediment}

Calcareous biogenic sediment is distinguished from terrigenous sediment and siliceous biogenic sediment by a biogenic $\mathrm{CaCO}_{3}$ content in excess of $30 \%$. There are two classes: (1) pelagic calcareous biogenic sediment that contains 60 to $100 \%$ biogenic $\mathrm{CaCO}_{3}$ (less than $30 \%$ silt and clay), and (2) transitional calcareous biogenic sediment that contains 30 to $60 \% \mathrm{CaCO}_{3}(>30 \%$ silt and clay). Only transitional biogenic calcareous sediment was recovered on Leg 96. These sediments were soft foraminifer-rich sediments and are therefore termed marly foraminiferal ooze.

\section{Terrigenous Sediments}

Terrigenous sediment is distinguished by a terrigenous component in excess of $30 \%$ and by siliceous and authigenic components each less than $10 \%$. Sediments in this category are subdivided into textural groups by macroscopic and/or smear slide estimation of the relative proportions of sand, silt, and clay. The Leg 96 shipboard sedimentologists used a simplified standard Shepard (1954) classification scheme for terrigenous sediments, in which mud is used as a less specific term for clay-siltsand mixtures (Fig. 5). The term mud was qualified by silty or clayey as appropriate. The size limits are those defined by Wentworth (1922) (Fig. 6).

\section{Volcanogenic Sediments}

Pyroclastic rocks are described according to the textural and compositional scheme of Wentworth and Williams (1932). The textural groups are (1) volcanic breccia: more than $32 \mathrm{~mm}$ in size, (2) volcanic lapilli: between 4 and $32 \mathrm{~mm}$ in size, and (3) volcanic ash: less than $4 \mathrm{~mm}$ in size (tuff when indurated). The composition of these pyroclastic rocks is described as vitric (glass), crystalline, or lithic. Volcanic ash layers were recovered only at Site 619; dispersed ash was recovered at Site 615; no volcanic breccia or lapilli layers were encountered.

\section{Biostratigraphy and Basis for Age Determination}

Microfossil zonation of sediments cored on Leg 96 was based on the scheme outlined in Figure 7, constructed using the following references:

1. Foraminifers: Blow (1969), Kennett and Huddlestun (1972), and Rogl and Bolli (1973).

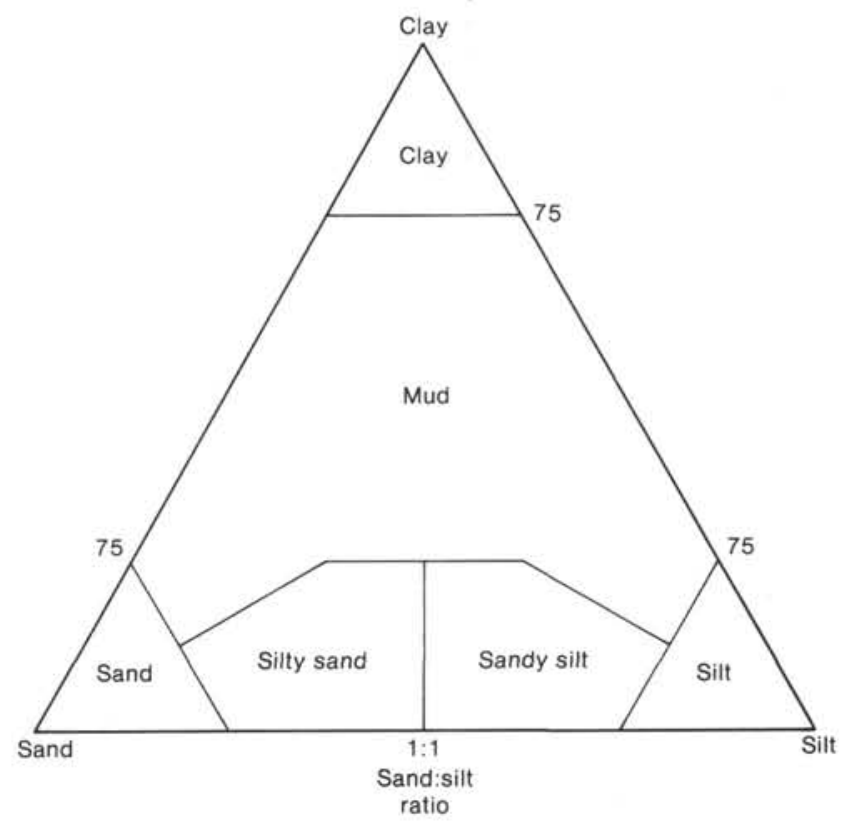

Figure 5. Triangular diagram showing classification scheme for terrigenous sediments used on DSDP Leg 96 (modified from Shephard, 1954). 


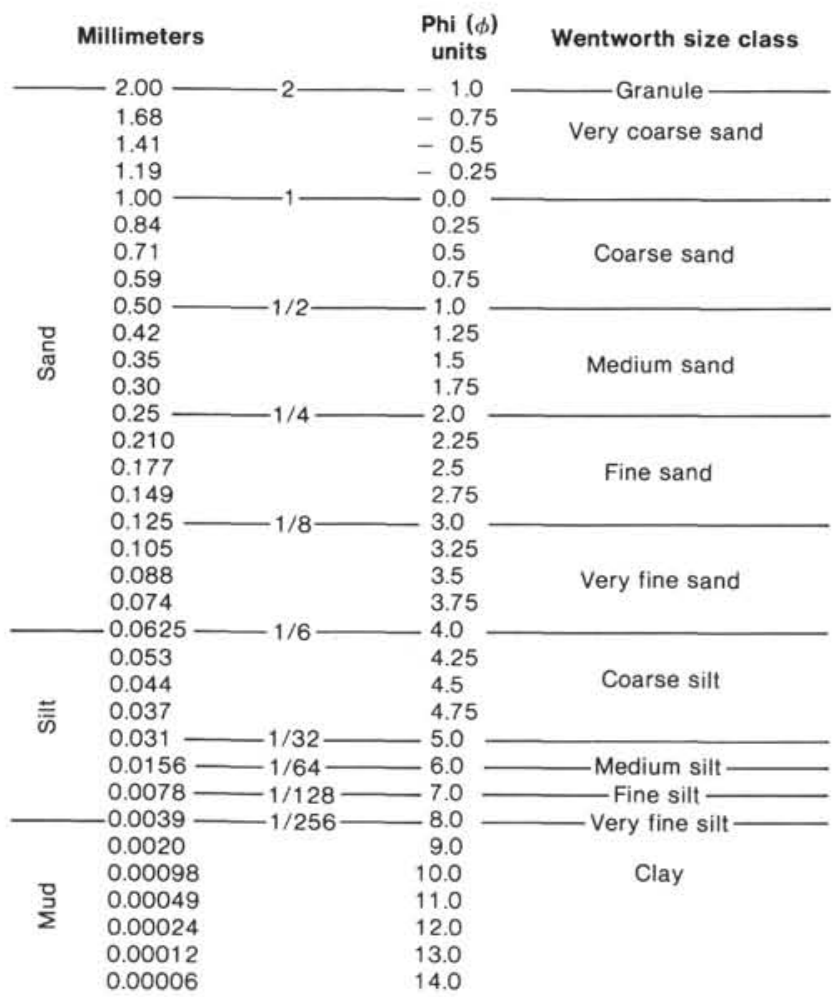

Figure 6. Grade scales for terrigenous sediments (from Wentworth, 1922).
2. Nannofossils: Martini (1971) and Gartner and Emiliani (1976).

3. Oxygen-isotope stratigraphy: Emiliani (1966), Ericson and Wollin (1968), Emiliani (1971), Thierstein et al. (1977), and Williams (1984).

4. Tephrochronology: Kennett and Huddlestun (1972) and Ledbetter (1984).

Downhole sedimentation rates were calculated on board ship from biostratigraphic results and are presented in the site chapters. These calculations assume the following ages for Ericson Zone boundaries: Z/Y boundary, 12,000 yr. ago; Y/X boundary, 85,000 yr. ago; and X/ W boundary, 127,000 yr. ago.

The following letters are used on the core description forms to indicate fossil abundance:

$\mathrm{A}=$ abundant (many species and specimens),

$\mathrm{C}=$ common (many species, easy to make age assignment),

$\mathrm{F}=$ few (scattered occurrences of diagnostic taxa),

$\mathrm{R}=$ rare (enough for age assignment), and

$\mathrm{B}=$ barren.

Letters used to designate fossil preservation are

$\mathrm{G}=\operatorname{good}($ very little dissolution or abrasion),

$\mathbf{M}=$ moderate (dissolution and/or abrasion and/or recrystallization very noticeable), and

$\mathrm{P}=$ poor (substantial or very strong evidence of dissolution and/or abrasion and/or recrystallization).

Most of the fossil microorganisms recovered in the Leg 96 sediments were reworked rather than in situ. Biostratigraphic samples that consist of reworked assemblages are indicated as such on the core description sheets by

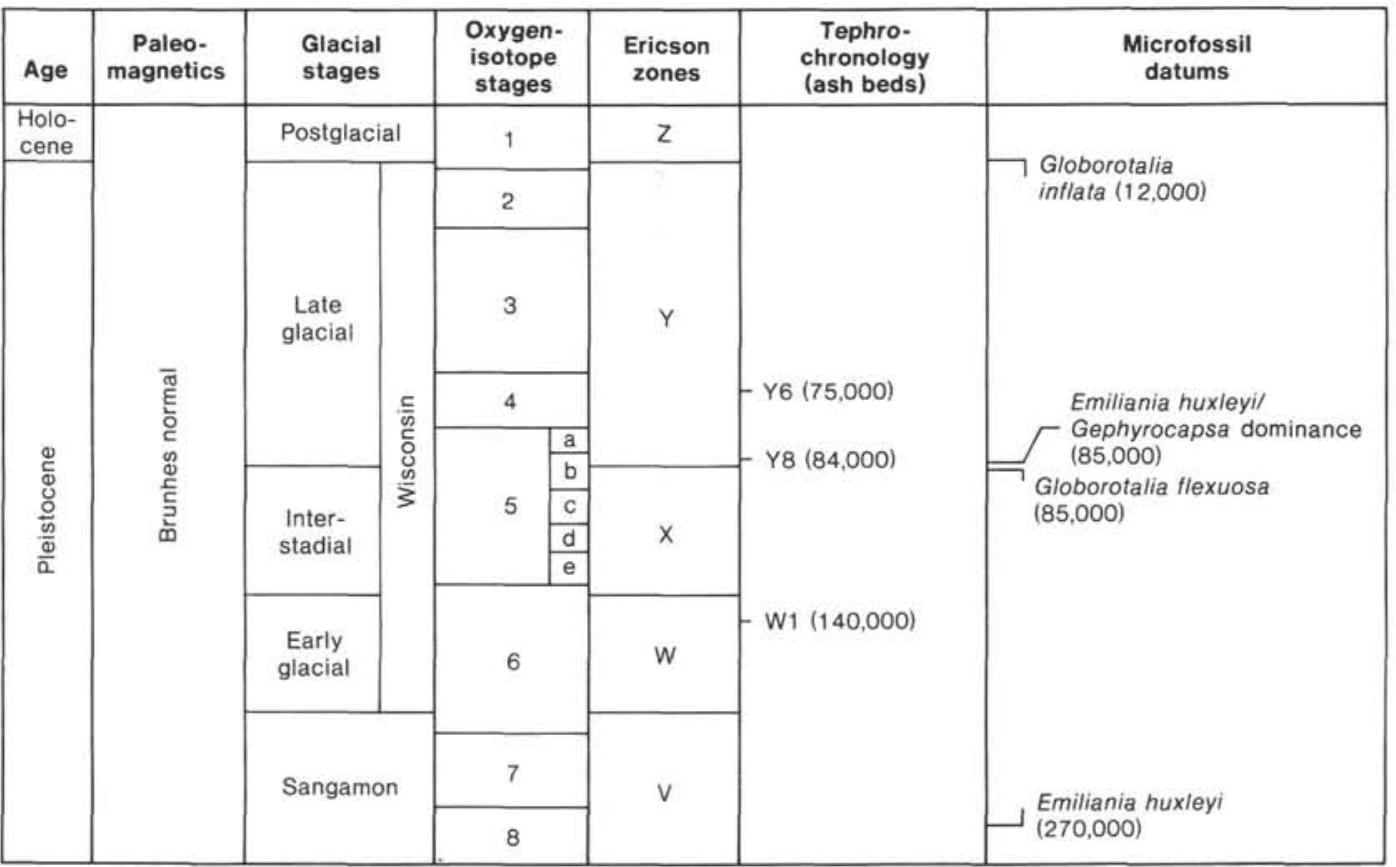

Figure 7. Late Quaternary zonation for the Gulf of Mexico. (From Emiliani, 1966; Ericson and Wollin, 1968; Blow, 1969; Emiliani, 1971; Martini, 1971; Kennett and Huddlestun, 1972; Rogl and Bolli, 1973; Gartner and Emiliani, 1976, Emiliani, 1966; Thierstein et al., 1977; Ledbetter, 1984; Williams, 1984.) Numbers in parentheses represent age of datums in years before present. 
circled abundance and preservation codes in the "Fossil Character" column (Fig. 2).

\section{SHIPBOARD GEOCHEMICAL MEASUREMENTS}

\section{Carbonate Bomb}

The percentage $\mathrm{CaCO}_{3}$ from selected intervals was determined on board ship by the carbonate-bomb technique of Müller and Gastner (1971). In this simple procedure, a sample is dried in an oven, ground to powder, and treated with $\mathrm{HCl}$ in a closed cylinder. Any resulting $\mathrm{CO}_{2}$ pressure is proportional to the $\mathrm{CaCO}_{3}$ content of the sample. Application of a calibration factor to the manometer reading $(\times 100)$ yields percentage $\mathrm{CaCO}_{3}$. Percentage error can be as low as $1 \%$ for sediments high in $\mathrm{CaCO}_{3}$; an accuracy of about 2 to $5 \%$ is generally expected.

Carbonate-bomb samples were obtained from the calcareous lithologic unit at Hole 615 and at selected intervals throughout the cores obtained at the other Leg 96 sites. These data are presented on the core description sheets (Fig. 2). The sample intervals for carbonate-bomb measurements are designated by two numbers: the section number, followed by the top of the sample interval. For example, a sample from Core 4, Section 2, 11-12 cm with $90 \%$ calcium carbonate will be represented on the core description sheet for Core 4 as " $2,11 \mathrm{~cm}=90 \%$ ". Locations of carbonate-bomb samples are shown in the "Samples" column.

\section{Interstitial Water}

Interstitial-water samples were routinely analyzed for $\mathrm{pH}$, alkalinity, and salinity on board ship. One sample was generally analyzed from every core; data from all these analyses are presented in the site chapters (this volume). The water samples were collected from sediments squeezed using a stainless steel press. The water was collected in plastic syringes and then filtered through $0.45-\mu \mathrm{m}, 13-\mathrm{mm}$ filters prior to analysis.

A Corning Model $130 \mathrm{pH}$ meter and a Markson combination electrode were used for $\mathrm{pH}$ measurements. The $\mathrm{pH}$ meter was calibrated with 4.01 and 7.42 buffer standards. Readings were originally made in millivolts and converted to $\mathrm{pH}$. All $\mathrm{pH}$ measurements are accompanied by alkalinity measurements.

Alkalinity was determined potentiometrically. Five to 10 -ml water samples were first tested for $\mathrm{pH}$ and then titrated with $0.1 \mathrm{~N} \mathrm{HCl}$. Near the titration end point, acid was added in $0.01-\mathrm{ml}$ or $0.005-\mathrm{ml}$ increments. Millivolt readings were noted for each increment. The exact end point was then calculated using the Gran Factor method (Gieskes and Rogers, 1973).

Salinity was calculated from the fluid refractive index, as measured by a Goldberg optical refractometer, using this expression:

$$
\text { Salinity }(\%)=0.55 \times \Delta N
$$

where $\Delta N$ is the refractive index multiplied by $10^{4}$. The refractometer's calibration was checked periodically using an IAPSO seawater standard and deionized water.
Calcium was determined by titrating a $0.5-\mathrm{ml}$ sample with EGTA using GHA as an indicator. To sharpen the end point, the calcium-GHA complex was extracted into a layer of butanol. No correction was made for strontium, which is also included in the result.

Magnesium was determined by titrating a buffered $0.5-\mathrm{ml}$ sample to an Erechrome Black-T end point using EDTA (sodium salt) as a titrant. This method was used to analyze all alkaline earths, including calcium, strontium, and magnesium; concentrations were obtained by subtracting the calcium (which includes strontium) from this analysis.

Chlorinity was determined by titrating a $0.1-\mathrm{ml}$ sample diluted with $1 \mathrm{ml}$ deionized water with silver nitrate to a potassium chromate end point.

Methods and equipment were checked and standardized at each site using IAPSO standard seawater. As a further check, a surface seawater sample was also analyzed and archived. This sample was also used to test for possible drill-water contamination of the interstitial water samples.

\section{Core Gas Analyses}

Samples were collected in "vacutainers" from gas expansion cracks either by drilling through the core liner or through the end caps of the sectioned cores. A rubber septum was pressed between the gas sampler and the core liner to minimize air contamination (although contamination of all samples occurs to some extent as a result of decompression of surface seawater drilling fluid as the cores are brought up from depth).

Because of persistent contamination in the $\mathrm{C}_{4}+$ hydrocarbon range of samples collected in commercially available "vacutainers," those used for all gas collection on Leg 96 were equipped with silicone-coated rubber stoppers. These tubes were prepared prior to the cruise in the laboratory of J. Whelan (Woods Hole Oceanographic Institution). They consisted of standard vacutainer rubber stoppers that were custom coated with silicone culture tubes and stoppers wired in place. The tubes were evacuated to less than 50 torr using a syringe needle attached to a high vacuum line. About $70 \%$ of the tubes prepared in this way continued to have good vacuum (as determined by a testa coil) 7 months after preparation. The vacuum in the tubes was tested with the testa coil just before use and with a vacuum gauge attached to a syringe needle inserted through the vacutainer septum at the time of gas sampling.

Gases were analyzed isothermically on a Carle packedcolumn gas chomatograph (GC) equipped with thermal conductivity detectors. Quantities were calculated with the external standard method using either peak heights or peak areas not detectable on the Carle GC. The more sensitive Hewlett-Packard GC, used on previous cruises, was not utilized in this work.

\section{PHYSICAL PROPERTIES}

\section{Methods and Procedures}

Physical properties measured on board the Glomar Challenger during Leg 96 included the following: (1) sat- 
urated-bulk density measured with a Gamma Ray Attenuation and Porosity Evaluator (GRAPE), (2) saturatedbulk density and water content with gravimetric analyses, (3) compressional-wave velocity, using the Hamilton Frame, and (4) shear-strength values, using both a mechanical and a hand-held device.

Most of the methods and procedures that were used to determine physical properties aboard the Glomar Challenger have been described in previous Initial Reports volumes (e.g., Boyce, 1976, 1977). For all measurements, the least-disturbed samples representing the predominant sediment type were chosen. Sand layers were commonly badly disturbed or not recovered. Therefore, most of the data were obtained from the more cohesive finer-grained sediments.

All the physical properties measured aboard the Glomar Challenger (except sound velocities) were made with the assumption that the sediments constitute a two-phase system composed of liquids and solids, that is, that the sediments are saturated with water.

The GRAPE was used to assess the saturated-bulk density of sediments from all the holes drilled during Leg 96. GRAPE analysis compares the attenuation of gamma rays through a sediment sample of unknown bulk density with that of a reference sample of known density. The main problem with assessing density from gamma ray attenuation measurements is that attenuation coefficients vary for different mineral types. Two GRAPE techniques were employed: (1) continuous GRAPE measurements, in which the entire, unsplit $1.5-\mathrm{m}$ sections were scanned to provide a continuous analog record of approximate bulk density, and (2) 2-min GRAPE scans, in which the gamma count was measured through a sediment sample contained in a 1-in. high, 1-in. diameter stainless steel cylinder capped by plexiglas end caps. The longer count times over an accurately known sediment thickness in the latter technique provide more reliable gamma counts. The calibration and calculation procedures are given in Boyce (1976). The 2-min GRAPE scan samples were later used as samples for shipboard gravimetric analyses.

Wet-bulk density and related parameters were determined using the cylinder technique described by Boyce (1976). The measurements are corrected for salt content assuming 35\% salinity and a water density of $1.024 \mathrm{~g} /$ $\mathrm{cm}^{3}$. Data scatter results from variations in the percentage composition of sand, silt, and clay.

Undrained shear strength was measured using either a hand-held torque watch and vane (a Soil Test Torvane) or a motorized vane-shear device equipped with a $1.25 \mathrm{~cm}$ by $1.25 \mathrm{~cm}$ vane rotated at approximately $90^{\circ} / \mathrm{min}$. Both instruments gave similar results.

Sonic velocity measurements were made with a Hamilton Frame velocimeter and/or a hand-held velocimeter designed and built by Sandia Corporation. The sediment samples were placed between and in contact with two transducers with a known separation distance. The Hamilton transducer has one fixed and one movable transducer, so that various sample sizes can be accommodated. The separation distance was read directly from a dial mounted on the frame. Velocities were measured on split cores contained in half rounds or on sediment cubes cut from the stiffer sediments. The cube sample velocities were measured perpendicular to and parallel to bedding in order to determine directional velocity anisotropy. The Sandia instrument consisted of two transducers mounted on fixed brass prongs $6.36 \mathrm{~cm}$ apart. The prongs were inserted directly into the working half of the split core.

Acoustic velocities are strongly attenuated by the presence of gas (in the bubble phase) in the interstitial waters of the sediment. As little as 0.1 to $1.0 \%$ gas in the pore water reduces the compressional-wave velocity by as much as $50 \%$. Attenuation increases exponentially with increasing gas volume. For all practical purposes, it was impossible to measure the velocity of gassy sediments with the equipment aboard the Glomar Challenger because of the large attenuation. Some gassy sediments have attenuations on the order of $200 \mathrm{~dB} / \mathrm{m}$. An interesting and seemingly contradictory fact concerning the velocity of gassy sediments is that when the amount of gas increases beyond a certain volume the compressional-wave velocity will actually increase. This is caused by a reduction in sediment density. In general, the presence of free gas in the sediment pore waters will: decrease bulk density, increase porosity and void ratio, decrease shear strength, decrease sound velocity (to a point), increase compressibility, and decrease water content by replacement.

\section{PHOTOGRAPHY}

Black and white photos of all the cores collected during Leg 96 are printed in the site chapters. In addition, both color core slides and black and white close-ups are archived at DSDP and are available for consultation.

\section{OBTAINING SAMPLES}

Potential investigators who want to obtain samples should refer to the Ocean Drilling Project-National Science Foundation (OPD-NSF) Sample Distribution Policy. Sample request forms may be obtained from the $\mathrm{Cu}$ rator, Ocean Drilling Program, Texas A\&M University, College Station, Texas 77843-3469. Requests must be as specific as possible: include site, hole, core, section, interval within a section, and volume of sample required.

\section{REFERENCES}

Blow, W. H., 1969. Late middle Eocene to Recent planktonic foraminiferal biostratigraphy. In Brönnimann, P., and Renz, H. H. (Eds.), Proc. Int. Conf. Planktonic Microfossils, Ist, Leiden (Brill), 6: 199-421.

Boyce, R. E., 1976. Definitions and laboratory techniques of compressional and sound velocity parameters and wet-water content, wet-bulk density, and porosity parameters by gravimetric and gamma ray attenuation techniques. In Schlanger, S. O., Jackson, E. D., et al., Init. Repts. DSDP, 33: Washington (U.S. Govt. Printing Office), 931-958.

1977. Deep Sea Drilling Project procedures for shear strength measurements of clayey sediment using modified Wykeham Farrance Laboratory Vane Apparatus. In Barker, P., Dalziel, I. W. D., et al., Init. Repts. DSDP, 36: Washington (U.S. Govt. Printing Office), 1059-1068.

Emiliani, C., 1966. Paleotemperature analysis of Caribbean cores P6304-8 and P6304-9 and a generalized temperature curve for the past 425,000 years. J. Geol., 74(2):109. 
1971. The last interglacial: paleotemperatures and chronology. Science, 171:571-573.

Ericson, D. B., and Wollin, G., 1968. Pleistocene climates and chronology in deep-sea sediments. Science, 162:1227-1234.

Gartner, S., and Emiliani, C., 1976. Nannofossil biostratigraphy and climatic stages of the Pleistocene. Am. Assoc. Pet. Geol. Bull., 60: $1562-1564$.

Gealy, E. L., Winterer, E. L., and Moberly, R. M., Jr., 1971. Methods, conventions, and general observations. In Winterer, E. L., Riedel, W. R., et al., Init. Repts. DSDP, 7, Pt. 1: Washington (U.S. Govt. Printing Office), 9-26.

Gieskes, J. M., and Rogers, W. C., 1973. Alkalinity determination in interstitial waters of marine sediments. J. Sediment. Petrol., 43: 272-277.

Kennett, J. P., and Huddlestun, P., 1972. Late Pleistocene paleoclimatology, Western Gulf of Mexico. Quat. Res., 2:38-69.

Ledbetter, M., 1984. Late Pleistocene tephrochronology in the Gulf of Mexico region. In Healy-Williams, N. (Ed.), Recent Advances in Pleistocene Stratigraphy Applied to the Gulf of Mexico: Boston (IHRDC Press), pp. 119-148.

Martini, E., 1971. Standard Tertiary and Quaternary calcareous nannoplankton zonation. In Farinacci, A. (Ed.), Proc. Planktonic Conf., 2nd: Rome (Edizioni Tecnoscienza), 2:739-785.

Matthews, D. J., 1939. Tables of the Velocity of Sound in Pore Water and in Seawater: London (Admiralty, Hydrographic Department).

Müller, G., and Gastner, M., 1971. The "Karbonat Bombe," a simple device for the determination of the carbonate content in sediments, soils and other materials. Neues. Jahrb. Mineral. Monatsh., 10: 466-469.

Rogl, F., and Bolli, H. M., 1973. Holocene to Pleistocene planktonic foraminifera of Leg 15, Site 147 (Cariaco Basin [Trench], Carribean Sea) and their climatic interpretation. In Edgar, N. T., Saunders, J. B., et al., Init. Repts. DSDP, 15: Washington (U.S. Govt. Printing Office), 553-615.

Shephard, F. P., 1954. Nomenclature based on sand-silt-clay ratios. J. Sediment. Petrol., 24:151-158.

Supko, P., Ross, D. A., and Neprochnov, Y. P., 1978. Introduction and explanatory notes, Leg 42B, Deep Sea Drilling Project. In Ross, D. A., Neprochnov, Y. P., et al., Init. Repts. DSDP, 42, Pt. 2: Washington (U.S. Govt. Printing Office), 3-15.

Thierstein, H. R., Geitzenauer, K., Molfino, B., and Shackleton, N. J., 1977. Global synchroneity of late Quaternary coccolith datums: validation by oxygen isotopes. Geology, 5:400-404.

Wentworth, C. K., 1922. A scale of grade and class terms of clastic sediments. J. Geol., 30:377-390.

Wentworth, C. K., and Williams, H., 1932. The classification and terminology of the pyroclastic rocks. Rept. Comm. Sedimentation, Bull. Natl. Res. Counc. (U.S.), 80:10-53.

Williams, D., 1984. Correlation of Pleistocene marine sediments of the Gulf of Mexico and other basins using oxygen isotope stratig raphy. In Healy-Williams, N. (Ed.), Recent Advances in Pleistocene Stratigraphy Applied to the Gulf of Mexico: Boston (IHRDC Press), pp. 65-118. 